\title{
Anticapitalismo e inserção social dos mercados
}

Ricardo Abramovay

Apresentação

O mais importante desafio da esquerda consiste em conter o avanço voraz da racionalidade econômica sobre a vida social. O que está em questão não é tanto a apropriação dos resultados ou dos meios materiais que permitem o exercício do trabalho: é, antes de tudo, a própria sociedade do trabalho. Não se trata de abolir seu pressuposto básico, o mercado. Trata-se sim de impedir que ele determine como os indivíduos organizam suas vidas e de ampliar ao máximo as formas de interação que não respondem às exigências mercantis. Isso não se alcança por meio de uma instância centralizada que substitua o mecanismo dos preços pelo planejamento, e sim pelo alargamento das formas de vida que não se apoiam no mercado e das quais os hackers, o movimento de softwares livres e o Creative Commons (http:// creativecommons.org/) são as expressões mais emblemáticas. Atividades comunitárias, cuidados pessoais, produção e difusão do conhecimento e da informação, valorização da biodiversidade e da integridade dos ecossistemas, relações afetivas são campos da existência ameaçados pelo mundo das mercadorias e, ao mesmo tempo, nos quais há um extraordinário potencial para construir novos modos de relações entre os indivíduos e com o mundo natural. O capitalismo não será ultrapassado pela apropriação coletiva dos grandes meios de produção e troca, e sim por uma transformação radical 
nos próprios modelos de produção e de consumo em que se baseia. $\mathrm{O}$ mercado é o contrário da autonomia individual: faz parte daquelas organizações em que a cooperação humana tem objetivos puramente funcionais e onde as tarefas especializadas são levadas adiante com base em finalidades que não são determinadas pelos indivíduos, mas definidas por uma racionalidade que lhes é externa, prescrita pela complexidade da própria organização. Mas essa heterorregulação pode ser também planejada, programada, como ocorre no caso do Estado e das grandes organizações privadas. $\mathrm{O}$ sombrio horizonte desenhado por essa dupla heterorregulação só pode ser enfrentado de forma construtiva caso a vida deixe de se organizar em torno do mercado, da empresa e da máquina administrativa, e tenha na esfera autorregulada da sociedade civil o seu eixo básico de articulação.

Aoposição entre mercado e sociedade civil fundamenta, na obra de André Gorz, uma ambiciosa proposta política, próxima ao que Jeremy Rifkin (2004), Philip Van Parijs (1996), Toni Negri e Giuseppe Cuoco (2006), Guy Aznar (1995) e Eduardo Suplicy (2002) (sob embocaduras intelectuais nem sempre idênticas, é verdade) chamam de renda de cidadania, alocação universal, renda mínima ou renda de inserção. O que está aí embutido, mais do que simplesmente uma forma de enfrentar a pobreza, é a mudança na própria maneira de encarar, produzir e consumir a riqueza. A separação radical entre o mundo das grandes organizações (espontâneas, como o mercado, ou planejadas, como o Estado e as corporações) e o da integração social, composta por laços imediatos, dotados de sentido existencial, é decisiva também na obra de Alain Touraine (2005) e, sobretudo, de Jürgen Habermas (1987). Produzir e consumir para quê? Essa pergunta só faz sentido fora das grandes organizações heterônomas, que hoje determinam de maneira destrutiva o uso do tempo e dos recursos por parte dos indivíduos. Quanto maior a capacidade de prover as necessidades humanas dotando-as de sentido existencial, aquecendo-as por laços sociais diretos, evitando que congelem sob o sopro das funções objetivas do mercado, da burocracia e das corporações, mais se avança numa direção oposta ao capitalismo.

Há, entretanto, uma vertente do pensamento contemporâneo, a nova sociologia econômica, que rejeita a suposta hostilidade sob a qual mercado

1.Estareduçãoétípica daobra de Gary Becker (1996) e do chamado marxismo analítico(cf. Elster, 1985). e sociedade são apresentados de maneira tão frequente. Não se trata, para essa corrente, de fundir mercado e sociedade, como se, em última análise, a vida dos indivíduos pudesse reduzir-se a um cálculo de natureza econômi$\mathrm{ca}^{1}$. A chamada nova sociologia econômica, que se afirma como disciplina científica nos Estados Unidos e na Europa desde meados dos anos de 1980 
e cujos autores principais são Mark Granovetter (1985), Neil Fligstein (2001), Viviana Zelizer (1997, 2004) e Philippe Steiner (2006), entre outros, considera o mercado como estrutura social e não como ponto de encontro entre atores anônimos, impessoais e que aí só podem relacionar-se de maneira efêmera. O principal desafio dessa corrente consiste em abrir aquilo que as ciências sociais habitualmente tratam como caixa-preta. $\mathrm{E}$ quando se abre a caixa-preta do mercado, o que se encontra em seu interior são laços sociais, é sociedade, são interações que os indivíduos procuram permanentemente dotar de significado. As consequências políticas dessa atitude são bem diferentes daquelas a que conduz o pensamento de André Gorz: não se trata tanto do esforço de resistir à tomada da vida social pelo mercado, construindo uma esfera específica de autonomia, e sim de compreender como se formam os mercados, em que valores, expectativas e realizações se apoiam, para então interferir permanentemente em sua organização, seja por meio do Estado, seja no interior da própria organização privada. Aplica-se a André Gorz a crítica dirigida pela nova sociologia econômica ao trabalho pioneiro e fundamental de Karl Polanyi (1980): faltalhes um estudo propriamente sociológico, empírico da maneira como, nas sociedades capitalistas contemporâneas, os mercados se organizam e interagem com as pressões sociais a que se submetem.

O objetivo deste artigo é expor os fundamentos a partir dos quais André Gorz preconiza a redução do tempo de trabalho, a renda de cidadania e o aumento das formas de colaboração social que não se apoiam no mercado como as bases de superação do capitalismo no mundo contemporâneo. A essa visão será contraposta aquela que hoje prevalece na nova sociologia econômica, em que não se trata de suprimir ou superar o capitalismo, mas de constatar a crescente incorporação, pelo próprio mercado e pela organização empresarial, de demandas vindas das aspirações e das pressões sociais. Longe de resultar em posição agnóstica ou conformista, o estudo empíricoconcreto, sociológico, dos mercados abre caminho para compreender e até preconizar transformações decisivas em suas estruturas.

\section{Ainevitável opacidade da máquina burocrático-industrial}

A obra de André Gorz organiza-se em torno de duas ambições básicas:

a) A primeira consiste em mostrar que a alienação, a distância que separa os indivíduos de si próprios e dos outros, não é apenas a consequência da exploração econômica, mas decorre da própria divisão do trabalho. Na pri- 
2. "O fracasso do panrracionalismo socialista não pode ser explicado apenas porrazõeshistóricaseempíricas. Suarazão profunda é ontológica:éontologicamente que a utopia marxiana que faz coincidir trabalho funcional e atividadepessoaléirrealizável naescaladosgrandessistemaspelofatoevidente de que ofuncionamento da megamáquinaindustrial burocráticaexige uma subordinação das tarefasque, umavez instalada, perpetua-see deve perpetuar-se por inércia, a fim de tornar viávelecalculávelafuncionalidadedecadauma das engrenagens humanas" (Gorz, 2003a, pp. 48-49). meira parte das Metamorfoses do trabalho, Gorz (2003a) discute com o próprio Marx (em cuja obra ele se apoia tão fortemente), procurando apontar um erro conceitual básico de sua formulação. Marx mostra de maneira genial (nos Grundrisse e no Livro I de $O$ capital) como o sistema de máquinas coloca inteiramente a seu serviço a atividade criativa, transformadora do trabalho humano. O elemento ativo, capaz de trazer algo novo para a vida social (o trabalho humano), converte-se em pura passividade, como se as máquinas adquirissem poder próprio. Essa ideia é fundamental, igualmente, no raciocínio desenvolvido por Karl Polanyi (1980) em A grande transformação, quando se refere à força destrutiva do "moinho satânico". No entanto, é o que mostra Gorz, essa inversão não decorre do capitalismo e não seria abolida caso o regime social de produção deixasse de ser capitalista. A relação de estranhamento entre o trabalhador e os meios materiais de produção (quer se trate de máquinas, de escritório ou de uma locomotiva) nãoé abolida pelo fato de ele não mais trabalhar para o capital e sim para o coletivo organizado dos operários que teriam controle sobre a produção social. A tentativa soviética de imprimir identidade existencial, sentido humano ao trabalho resultou no stakhanovismo, que em nada se distinguia das piores práticas administrativas aplicadas nas sociedades capitalistas. O projeto político que consiste em ultrapassar o capitalismo por meio da expropriação dos grandes meios de produção e troca e da substituição generalizada do mercado pelo planejamento central padece do vício de imaginar que uma organização social complexa pode ser perfeitamente transparente aos olhos de seus participantes e, por aí, então, gerida de forma democrática. As megaorganizações privadas e públicas características das atuais sociedades de massa são necessariamente opacas, quaisquer que sejam as regras de alocação e distribuição da propriedade e dos resultados do trabalho. É cientificista e tecnocrático o mito de que o controle do Estado pela sociedade organizada pode oferecer imagem visível, compreensível do funcionamento das grandes organizações, a ponto de permitir o planejamento democrático e participativo. Essa crítica marca a trajetória intelectual de André Gorz e consolida-se na obra visionária que, publicada em 1988 (um ano antes da queda do Muro de Berlim), mostrava que a inviabilidade dos regimes de planejamento central não decorria de circunstâncias históricas particulares (da destruição da vanguarda operária russa durante a Guerra Civil dos anos de 1920, ou de um suposto desvio de rota representado pelo stalinismo, por exemplo), mas sim do equívoco de imaginar que o trabalho fabril pode ser emancipador, uma vez despojado de sua natureza capitalista ${ }^{2}$. 
b) A segunda ambição fundamental de Gorz é definir em que pode consistir a emancipação humana nas sociedades contemporâneas. A influência do pensamento de Sartre, nesse sentido, é decisiva, como Gorz o reconhece na entrevista que abre a obra póstuma Écologica (2008). Sua posiçãolembra a célebre tirada de Rimbaud ("je est un autre", eu é um outro), quando ele afirma: "não é 'eu' que age” (“ce n'est pas 'je' qui agit”), é a lógica automatizada dos agenciamentos sociais que age através de mim enquanto Outro, me faz contribuir à produção e reprodução da megamáquina social. É ela o verdadeiro sujeito" (Gorz, 2008, p. 12). A emancipação humana, para Gorz, não passa por suprimir o capital numa organização em que a vida continuaria submetida a organizações heterônomas, sobre as quais o indivíduo não tem como exercer poder, nem atribuir sentido, e sim pela reconstrução do sujeito, por espaços crescentes de autonomia e de vida comunitária, em que o cotidiano escapa ao caráter mecânico que as grandes estruturas procuram lhe imprimir por meio do consumo e das atividades programadas no trabalho.

Como, porém, compatibilizar o projeto emancipador de afirmação do sujeito individual, sua capacidade construtiva de insubmissão contra a megamáquina industrial-burocrática, com a existência objetiva dessas organizações e com o fato de elas preencherem funções úteis e essenciais na provisão de bens e serviços? A resposta convencional do movimento socialista (a submissão da máquina burocrático-industrial ao controle organizado dos trabalhadores, por meio da expropriação dos grandes meios de produção e troca) é, para Gorz, catastrófica e está na origem da tragédia ocorrida com o mundo socialista.

É verdade que Gorz, crítico contundente da utilidade dessas funções essenciais, mostra ao longo de toda sua obra que o próprio consumo resulta da submissão do indivíduo às organizações heterônomas que buscam permanentemente determinar sua vida. No curto relato biográfico contido na introdução de Écologica, ele explica:

Meu ponto de partida foi um artigo publicado num semanário norte-americano em 1954. Ele explicava que a valorização das capacidades de produção americanas exigia que o consumo crescesse ao menos $50 \%$ nos próximos oito anos, mas que as pessoas seriam incapazes de definir de que seriam feitos seus $50 \%$ de consumo suplementar (Idem, p. 14).

Essa definição viria dos especialistas em publicidade e marketing, responsáveis por suscitar necessidades e desejos capazes de promover o funcio- 
namento do sistema econômico. Daí resulta a importância, na obra de Gorz, de seu vínculo com a ecologia política, ou seja, sua abordagem teoricamente crítica tanto da formação das necessidades, como da própria técnica (a "tecnocrítica", para usar sua expressão), aspectos em que o trabalho de Ivan Illitch influenciou de maneira tão fundamental seu pensamento:

Illich distinguia duas espécies de técnicas: as que ele chamava de propícias à convivência (conviviales), que aumentam o campo da autonomia, e aquelas, heterônomas, que o restringem ou o suprimem. Eu [Gorz] as chamei "tecnologias abertas" e "tecnologias ferrolho". São abertas as que favorecem a comunicação, a cooperação, a interação, como o telefone ou, atualmente, as redes de softwares de livre acesso. As "tecnologias ferrolho" são as que submetem o usuário, programam suas operações, monopolizam a oferta de um produto ou de um serviço (Idem, p. 16).

Isso não significa, no entanto, que se possa preconizar como programa político a supressão dessas "tecnologias ferrolho", das empresas vinculadas à sua produção ou dos mercados aos quais se dirigem seus produtos. O notável na obra de André Gorz (sobretudo em Metamorfoses do trabalho) é que a crítica à maneira como se formam e difundem os padrões de produção e consumo no capitalismo não se faz sob um registro tradicionalista e baseado em melancólica utopia de volta ao passado. Ao contrário, a crítica da razão econômica não conduz à proposta de sua pura e simples supressão. É necessário delimitá-la, restringir sua expansão, mas ao mesmo tempo seria absurdo negar o papel decisivo que a racionalidade econômica (a expressão mais emblemática da esfera da heteronomia da vida social) desempenha no mundo contemporâneo. Vejamos a questão mais de perto.

\section{O mercado como esfera pública}

A crítica ao capitalismo e à alienação nele necessariamente contida não conduz Gorz a preconizar a abolição do mercado e da racionalidade econômica. Ele se separa, nesse sentido, não apenas do que se pretendeu levar adiante na construção das economias centralmente planificadas, mas do projeto que dominou a esquerda no século XX: mudar o conteúdo e o modo de funcionamento da economia contemporânea suprimindo sua natureza capitalista, colocando-a a serviço do coletivo organizado dos trabalhadores. Que essa supressão seja feita de forma violenta (por meio da ditadura do proletariado) ou pacífica (pela conquista eleitoral do poder, como 
o preconizava o eurocomunismo), Gorz critica a ideia de que o controle estatal dos grandes meios de produção e troca é capaz de abrir caminho para que a alocação e a distribuição dos recursos respondam (uma vez abolida a propriedade capitalista) às necessidades sociais e não mais ao lucro.

Para Gorz a ambição contida nesse projeto é duplamente ilusória. De um lado, ela supõe que a gestão de grandes organizações complexas, uma vez suprimida sua sujeição ao capital, pode tornar-se uma questão técnica, cujos conteúdo e métodos seriam amplamente acessíveis e, portanto, passíveis de um planejamento verdadeiramente participativo. A parábola de Lênin sobre o planejamento sendo levado adiante por qualquer cidadão, até por uma cozinheira, é emblemática nesse sentido e supõe que a supressão do fetichismo da mercadoria e do capital é condição necessária e suficiente para abolir a opacidade do mundo social. Gorz cita a célebre passagem do final da Ética protestante e o espírito do capitalismo em que Max Weber usa expressões como "petrificação mecanizada", "especialistas sem espírito", "sensualistas sem coração", e conclui que "o funcionamento da megamáquina burocrático-industrial e a motivação de seus felás a funcionarem como engrenagens, colocaram-lhes problemas de regulação cada vez mais difíceis de resolver. Nenhuma racionalidade, nenhuma visão totalizante podiam assegurar um sentido, uma coesão, um fio condutor ao conjunto" (Gorz, 2003a, p. 45).

A segunda fonte de ilusão contida nessa utopia totalizante explica a própria ineficiência do aparato produtivo das economias centralmente planificadas até a queda do Muro de Berlim. As sociedades modernas não podem simplesmente abolir o "trabalho racional no sentido econômico" (Idem, p. 135), cujo traço essencial é a busca de eficiência e não de significado:

[...] o trabalho efetuado em vista de sua troca mercantil, por mais interessante que seja, não pode estar no mesmo plano da atividade do pintor, do escritor, do missionário, do pesquisador, do revolucionário etc., que aceitam viver na privação porque é sua própria atividade que serve para eles de objetivo primário e não o valor de troca dessa atividade" (Idem, p. 136).

Existe um vasto campo da vida social em que as atividades mercantis e o mercado justificam-se de forma perene por sua capacidade técnica de oferecer bens inacessíveis à produção doméstica, artesanal, artística ou resultante do trabalho voluntário. As atividades mercantis são socialmente nefastas ali onde não aumentam em nada a produtividade do trabalho, nem contribu- 
em para reduzir o esforço social na oferta de bens e serviços: é o caso dos serviços de proximidade, dos cuidados pessoais, da vida afetiva, bem como da construção dos vínculos sociais de proximidade. Mas a lógica que preside a formação desses vínculos é totalmente incompatível com aquela que rege a vida numa organização destinada à produção de aviões ou à gestão da rede elétrica de uma região, e onde a rígida divisão do trabalho, a disciplina da fábrica e a intransparência da hierarquia na atribuição das tarefas são inevitáveis. Uma vez que essas atividades mercantis são levadas adiante numa esfera pública (o mercado), trazem consigo uma forma decisiva de reconhecimento social: "o fato de uma atividade ser objeto de troca mercantil na esfera pública denota, de princípio, que se trata de uma atividade socialmente útil, criadora de um valor de uso socialmente reconhecido como tal". Não há qualquer tipo de vínculo afetivo, pessoal ou comunitário nessas relações sociais: "os próprios clientes, aliás, não me pedem para trabalhar para eles como pessoas privadas (como se pede a um empregado doméstico, por exemplo), mas para fazer um trabalho determinado em condições e preços determinados". Essa é a razão pela qual "o trabalho remunerado na esfera pública é fator de inserção social" (Idem, pp. 137-138).

Aracionalidade econômica deve aplicar-se às atividades que preenchem quatro condições básicas: “a) criam valor de uso; b) têm em vista uma troca mercantil; c) realizam-se na esfera pública e d) em um tempo mensurável, e com um rendimento o mais elevado possível" (Idem, p. 137).

Fazer o trabalho doméstico com base no assalariamento, por exemplo, não tem qualquer utilidade social, pois não aumenta a eficiência global na realização do serviço a ele associado. $\mathrm{O}$ fato de o trabalho doméstico representar a criação de um "emprego" não é suficiente para justificá-lo: trata-se de um emprego que em nada contribui para melhorar a capacidade social de oferecer um determinado bem ou serviço. Da mesma forma, liberar alguém do trabalho doméstico ou do cuidado com os filhos em nome da preservação de sua capacidade produtiva na esfera mercantil a que se dedica tampouco tem sentido social e mostra apenas a imensa dificuldade em partilhar o tempo de trabalho entre os indivíduos para que todos possam trabalhar (cada vez menos) dedicando-se (cada vez mais) a atividades dotadas de sentido pessoal e comunitário.

A grande contradição do capitalismo é que as atividades heterônomas, levadas adiante na esfera pública do mercado, exatamente por se sujeitarem à concorrência, são poupadoras e não criadoras de trabalho. É cada vez menor o tempo que a sociedade dedica à produção desses bens e serviços, cuja 
oferta passa pela esfera mercantil. Só que em vez de essa consequência da inovação e do progresso técnico ser colocada a serviço da sociedade (liberando os indivíduos do trabalho), ela se traduz em crise e em desemprego. Pior: o aumento potencial do tempo socialmente livre decorrente da elevação da produtividade do trabalho traduz-se no esforço de gerar emprego e na tentativa obstinada de fazer da vida pessoal e comunitária, dos cuidados como meio ambiente, da troca livre de conhecimentos e informação um campo de trocas mercantis, quando nada justifica - sob o ângulo da pura eficiência econômica - que esses terrenos se submetam à lógica do mercado. Em vez de organizar a gestão de uma quantidade cada vez maior de tempo livre, o capitalismo contemporâneo procura, cada vez mais, economicizar ${ }^{3}$ esse tempo, submetê-lo a uma racionalidade que em nada lhe agrega em termos de eficiência, embora possa representar a criação de mais "empregos".

A originalidade da posição de Gorz reside na elaboração de um caminho inteiramente descentralizado para a construção de uma sociedade não capitalista. Eé exatamente por isso que ele pode afirmar, no primeiro capítulo de Écologica, que "a saída do capitalismo já começou” (Gorz, 2008, p. 25): essa saída não depende da tomada do poder político, da expropriação dos meios de produção e troca ou do planejamento central.

[...] as empresas já vêm trabalhando em boa medida no âmbito de redes, unindose nos momentos de tomada de decisão. A auto-organização, a autocoordenação e a livre troca estão hoje na base da produção social. E são realizadas sem a necessidade de um planejamento central nem da intermediação do mercado. Os produtores, que se relacionam entre si em redes, colocam-se em comum acordo preventivamente e de maneira pactuada para produzir em função das necessidades, desenvolvendo sua função produtiva como um complexo de atividades essencialmente coletivas, promovendo um intercâmbio de bens e serviços sem que tenha sido previamente acertado o caráter dessas mercadorias. O dinheiro torna-se então supérfluo, e o capital teria assim sua própria base capturada (Gorz, 2003b, s. p.).

A consequência é o alargamento das áreas em que a oferta de bens e serviços (e, portanto, a própria produção das necessidades a eles associadas) escapa à dominação capitalista.

Numa linha de raciocínio muito próxima à desenvolvida por Benkler (2006), Lerner e Tirole (2002) e Lessig (2001), Gorz mostra, por exemplo, que não há qualquer ganho social na obstinada tentativa de privatizar a economia do conhecimento e da informação (cf. Gorz, 2003b). Elas têm por base
3. Economicizar é um termo empregado por Gorz. Significa fazerentrar na esfera econômica algo que, de maneira precípua, não lhe pertence. 
[...] uma riqueza com a vocação de ser um bem comum [...] a área da gratuidade se estende irresistivelmente. A informática e a internet minam o reino da mercadoria em sua base. Tudo o que é traduzível em linguagem informatizada e reprodutível, comunicável sem despesa, tende irresistivelmente a transformar-se em bem comum e até em bem comum universal quando acessível a todos e utilizável por todos" (Gorz, 2008, p. 37).

É isso que define o conflito central de nossa época:

[...] ele se estende e se prolonga na luta contra a mercantilização das riquezas primeiras - a terra, as sementes, o genoma, os bens culturais, os saberes e competências comuns, constitutivos da cultura cotidiana e que são as premissas da existência de uma sociedade. Do feitio dessa luta depende a forma civilizada ou bárbara que tomará a saída do capitalismo (Idem, p. 39).

\section{Aexcelente síntese de} Steiner (2000) é uma exceção. Num ambiente em que predomina a indiferença, chamam a atenção o preconceito e a superficialidade que permitem a Swedberg lançar a pérola de que, "por muitas razões, é óbvio que a sociologia econômica não pode aceitar o Marxismo em seus próprios termos". Só quem tem um conhecimento precário da obra e do método de Marx pode afirmar que "ele era obcecado pelo papel da economia na sociedade e desenvolveu uma teoria em que a economia determina a evolução geral da sociedade" (Swedberg, 2003, pp. 8-10).
O surgimento da internet fortaleceu um ambiente no qual emergem formas de ação coletiva que não se baseiam nem no sistema de preços nem nas modalidades coordenadas de práticas típicas das firmas ou dos grupos de firmas. A internet oferece uma plataforma de comunicação que fortalece a ação em rede dos indivíduos.

\section{Inserindo o mercado na vida social}

A obra de Gorz não deu lugar, infelizmente, a nenhuma análise explícita por parte dos nomes mais expressivos da sociologia econômica contemporânea. O diálogo entre essa corrente de pensamento e os autores de inspiração marxista é, de fato, muito precário. O uso de referenciais teóricos apoiados em Marx é quase inexistente ${ }^{4}$. Em contrapartida, a nova sociologia econômica tem relação muito próxima com a obra de um dos inspiradores de Gorz: Karl Polanyi, para quem, da mesma forma que em Gorz, o mercado tende a se apropriar de domínios da existência social que não respondem e não podem responder à sua lógica própria. Polanyi insiste na ideia de que terra, trabalho e dinheiro não passam de "mercadorias fictícias", frutos da ilusão utópica de fazer da natureza, do próprio homem e dos laços sociais parte da economia de mercado. A sociedade organiza-se sob diferentes formas para reagir a essa invasão permanente, e a construção do Estado de Bem-estar exprime uma das mais interessantes formas dessa reação. 
Mas o esforço analítico de examinar o mercado como imerso na vida social se concentrou, no caso de Polanyi, em sociedades não capitalistas. A crítica que lhe dirige Mark Granovetter (1985) no texto de fundação da nova sociologia econômica é que ele não estuda empiricamente as determinações sociais, histórico-concretas dos mercados existentes no próprio capitalismo. Não o faz exatamente por estipular o mercado como esfera autônoma da vida social, como se respondesse a uma lógica dada de antemão por suas funções essenciais 5 :

Foi majoritária, durante muito tempo, entre sociólogos, antropólogos, cientistas políticos e historiadores, a visão de que o comportamento econômico estava profundamente imerso nas relações sociais em sociedades pré-mercantis e tornou-se muito mais autônomo com a modernização. Esse ponto de vista encara a economia como uma esfera crescentemente separada, diferenciada, na sociedade moderna, onde as transações econômicas não são mais definidas por obrigações sociais ou de parentesco daqueles que transacionam e sim por cálculos racionais, voltados aos ganhos dos indivíduos (Granovetter, 1985, p. 482).

Esse processo de separação e diferenciação faz parte da melhor tradição das ciências sociais contemporâneas. $\mathrm{O}$ fetichismo da mercadoria, por exemplo, só pode existir ali onde os vínculos de mercado se apoiam no "estranhamento recíproco", para usar a expressão de Marx, entre os que dele fazem parte, quando os indivíduos se reconhecem exclusivamente na qualidade de portadores dos bens e serviços que transacionam de forma anônima e impessoal. O mercado que vai resultar na formação do capitalismo supõe que não haja laços de dependência pessoal entre seus participantes. Vínculos sociais de real cooperação só podem ser alcançados quando a opacidade característica do mundo das mercadorias for suprimida em benefício de uma organização racional, capaz de representar aos olhos de seus participantes a verdadeira natureza de sua ligação.

No último (e inacabado) capítulo do volume I de Economia e sociedade, Max Weber - num registro que faz pensar em Marx - afirma:

Quando o mercado é deixado à sua legalidade intrínseca, leva apenas em consideração a coisa, não a pessoa, inexistindo para ele deveres de fraternidade e devoção ou qualquer das relações humanas originárias sustentadas pelas comunidades pessoais [...]. O mercado, em contraposição a todas as demais relações comunitárias que sempre pressupõem a confraternização pessoal e na maioria
5. A interessante crítica de Gemici (2008) vai exatamente na mesma direção. 
das vezes a consanguinidade, é estranho, já na raiz, a toda confraternização (Weber, 1991, p. 420).

Apesar das embocaduras tão distintas que fundamentam essas análises, em ambos os casos há uma fissura intransponível entre mercado e vida comunitária, entre as relações que se apoiam exclusivamente nos mecanismos de preços e a interação social baseada em laços concretamente identificáveis. É sobre a base dessa tradição que Gorz denuncia a propensão destrutiva do mercado de apropriar-se de domínios da vida social em que sua presença pode representar ganhos empresariais, mas não aumento de eficiência social.E mesmo onde o mercado é reconhecido como esfera pública legítima de afirmação dos indivíduos, não é ali que se encontra o domínio em que podem ser construídos significados e modalidades de interação capazes de imprimir sentido à vida dos indivíduos uns com os outros.

Uma das mais importantes preocupações da nova sociologia econômica consiste em estudar os mercados como construções sociais e não como entidades mágicas e diabólicas cujo funcionamento corrói a cultura, a ciência e os próprios vínculos sociais. Portanto, os mercados não serão vistos como esfera institucional autônoma da vida social e sim analisados a partir de sua construção social. Isso envolve uma crítica tanto à ideia canônica dos manuais de economia em que mercados são mecanismos neutros de equilíbrio entre indivíduos isolados uns dos outros, como à noção de que são fatores de corrupção e pasteurização da cultura humana e das formas mais nobres de existência social. Mercados não são entidades impessoais em que unidades autônomas e anônimas se encontram de maneira ocasional, orientados pelos sinais emitidos pelos preços. Mas tampouco são formas em que os indivíduos apenas obedecem, sem o saber, a determinações que vão além de sua capacidade e de sua vontade.

Há ao menos três campos de estudos empíricos que ilustram o teor das críticas que a nova sociologia econômica dirige a abordagens como a de Gorz, discutidos a seguir.

\section{A economia da informação em rede}

Nos últimos anos de sua vida Gorz testemunhou a expansão de um fenômeno que materializava o caminho por ele preconizado na luta contra o capitalismo. Em $O$ imaterial, ele mostra que o capitalismo é incapaz de transformar a abundância da inteligência humana - expressa em redes cada 
vez mais difusas e complexas - em escassez e, portanto, de fazer dela fonte de lucro (cf. Gorz, 2005, p. 69). É o que explica a própria crise do "capitalismo do saber" e o extraordinário potencial de emancipação que ela abre. O capitalismo quer apropriar-se da inteligência coletiva e "economicizar" as atividades e as riquezas que ela é capaz de produzir. A ele se opõem os que Gorz (2005, p. 63) chama de "dissidentes do capitalismo digital", muitos dos quais têm na partilha do conhecimento e da informação um preceito ético decisivo da maneira como levam adiante suas atividades: "a atividade do hacker repousa numa ética de cooperação voluntária, na qual cada um se compara aos outros pela qualidade e pelo valor de uso da sua contribuição para seu grupo, coordenando-se livremente com eles. Nada se produz com a finalidade de trocas comerciais" (Idem, p. 67).

Ainda que sob registros diferentes, esse mesmo tipo de análise pode ser encontrado numa importante literatura que estuda a emergência da "economia da informação em rede", para usar a expressão de Benkler (2006): "Na economia da informação em rede, o capital físico que se requer para a produção é amplamente distribuído pela sociedade". Isso abre caminho a que os indivíduos interajam como seres humanos, como seres sociais, mais que como atores de mercado (cf. Idem, pp. 5-6).

O problema dessa abordagem é que tudo se passa como se estivesse surgindo uma sociedade livre de estruturas e de coerções e em que a cooperação humana se despoja de qualquer forma de hierarquia e dominação, para exprimir apenas a riqueza das próprias redes. É bem verdade, como insistem Gorz e Benkler, que as possibilidades da cooperação aumentaram e se diversificaram muito. Entretanto, essa cooperação vai combinar sempre formas mercantis e não mercantis, e nessa combinação serão estabelecidas modalidades de dominação que não podem ser ignoradas. O que o trabalho de Mark Granovetter, por exemplo, procura mostrar é que as redes sociais, a cultura informal, o estabelecimento de códigos implícitos e, mais que isso, os laços personalizados de lealdade, os compromissos localizados, os vínculos afetivos e a atribuição de significados são parte integrante do funcionamento dos mercados e não expressões tradicionais que seu desenvolvimento contemporâneo seria capaz de extirpar. O fluxo de informações necessário ao funcionamento do mercado não tem nada de automático ou impessoal. As atividades mercantis supõem vínculos de confiança que vêm de fontes não pertencentes estritamente às relações mercantis (cf. Granovetter, 2005).

Inversamente, é preciso procurar na difusão livre e aberta da cultura, do conhecimento e da informação as estruturas sociais, as formas de domina- 
ção que, apesar das intenções explícitas de seus participantes, lhes são subjacentes. Estudo realizado, por exemplo, sobre o paradoxo de os produtores culturais ligados ao tecnobrega paraense estimularem a divulgação de seu trabalho por meio de CDs oferecidos quase gratuitamente mostra a existência de uma clara hierarquia entre os que participam dessa atividade. A oferta gratuita de gravações musicais tem como contrapartida o poder dos donos das aparelhagens sobre a organização de shows lucrativos, bem como uma entrada altamente seletiva na publicidade veiculada pelas emissoras de rádio (cf. Favareto et al., 2007).

A maneira como Gorz (e Benkler) encara o potencial emancipatório da economia da informação em rede é, portanto, objeto de duas críticas importantes. De um lado, Gorz e Benkler parecem não perceber que o próprio mercado não poderia funcionar se não se apoiasse em formas de sociabilidade não restritas a propriedades e contratos, o que significa ao menos um grão de sal na oposição tão marcada entre o calor das relações humanas significativas e a fria objetividade daquilo que seria próprio ao mercado. A segunda crítica é que tudo se passa como se a extensão da área de gratuidade que acompanha a internet conduzisse a formas de interação desprovidas de estruturas hierárquicas de dominação. No caso do tecnobrega paraense, a presença dessa hierarquia é nítida. Quanto aos domínios em que agem os hackers, uma abordagem sociológica procuraria aí formas de dominação social, estruturas que se impõem - apesar da supressão da propriedade privada e do esforço de fazer da rede um espaço genuíno e voluntário de cooperação humana.

\section{Mercados contestáveis e singularidades}

Em 1974, constatando perigosa pasteurização do "discurso ecológico" e a emergência de uma ecologia de direita, Gorz publica em Les Temps Modernes um artigo-manifesto em que alerta contra o perigo de que a defesa do meio ambiente seja inteiramente recuperada pelos interesses dominantes. "O que queremos? Um capitalismo capaz de se acomodar diante das pressões ecológicas ou uma revolução econômica, social e cultural que represente a abolição do capitalismo e, por aí, instaure uma nova relação dos homens com a coletividade, com seu meio ambiente e com a natureza? Reforma ou revolução?" (Gorz, 1974, s. p.).

O que está totalmente ausente do horizonte de Gorz (tanto nesse texto de 1974, como em seu trabalho posterior) é a ideia de que mercados po- 
dem ser espaços de expressão de importantes pressões e mesmo de mudanças sociais. O que a sociologia econômica contemporânea procura trazer à tona é a ideia de que existe dependência mútua entre corporações e sociedade. O trabalho de Andrew Hoffman (2001) sobre o surgimento do ambientalismo corporativo nos Estados Unidos é um excelente exemplo nessa direção. Longe de tratar o tema como esforço ardiloso das empresas em lançar cortina de fumaça capaz de sacrificar os anéis para salvar os dedos, Hoffman escreve uma história institucional do que chama ambientalismo corporativo nos Estados Unidos. Inspirado, em grande parte, no trabalho de Pierre Bourdieu, ele mostra a organização empresarial como campo social, permanentemente atravessado pela ação de militantes, pelas decisões do governo e pela própria reputação da firma. As escolhas das empresas não envolvem apenas seleção de tecnologias, preços e procedimentos produtivos, mas também a maneira como vão relacionar-se com as dimensões socioambientais do que fazem. O "índice de acesso aos medicamentos" (www.atmindex.org), por exemplo, chama a atenção nesse sentido, pela natureza surpreendente da parceria entre importantes organizações não governamentais (como a Oxfam ou a Icco, por exemplo) e a indústria farmacêutica na formulação de indicadores capazes de mostrar qual a utilidade social daquilo que o setor produz. Não se trata de filantropia ou de trabalho social paralelo às atividades industriais, e sim do que ocorre no interior do próprio mercado. O "índice de acesso aos medicamentos" põe em questão o modelo tradicional, em que os grandes laboratórios ganham basicamente pela proteção dos direitos de acesso à inovação. Esse modelo está em franca contestação pelas sistemáticas quebras de patente que a Justiça vem impondo em diversos países. Assim, a afirmação da Oxfam de que é necessário à indústria encontrar novas formas de fazer negócios, nas quais a responsabilidade pelo acesso aos medicamentos faça parte do foco principal (core business) da empresa, é muito mais que um desejo. O índice é elaborado por atores sociais diversos: indústria, universidade, consultores, governos, organizações religiosas e a própria Oxfam. Ele atribui pesos a vários aspectos do comportamento do setor que jamais se exprimiriam em seus balanços contábeis. A maneira como os laboratórios fazem a gestão do acesso aos medicamentos, as consequências de suas pesquisas sobre o combate às chamadas doenças negligenciadas, o caráter equitativo de sua política de preços, políticas de patentes e de licenciamento são alguns dos itens que entram no índice. Alguns fundos de investimento adotarão o índice como critério para suas aplicações no setor. 
6. O trabalho de Ana Célia Castro (2007) sobre catching-up na indústria agroalimentar brasileira também insiste na inserção dos mercados como base para sua transformação.
No mesmo sentido, Thierry Hommel e Olivier Godard (2001) perguntam: por que razão, nos últimos vinte anos, é tão importante a ação de grandes empresas que, em vez de esperar imposições do poder público, antecipam-se e dotam-se de cartas, protocolos e acordos voltados a reduzir os impactos ambientais negativos daquilo que fazem? Não se trata de uma apologia da livre iniciativa, pela qual as empresas poderiam resolver os desafios ambientais sem a fiscalização estatal. O importante é que as empresas estudadas por Hommel e Godard não se isolam do ambiente social em que vivem. Assim, são levadas a organizar o que chamam de "gestão antecipada da contestabilidade": os lucros de uma grande empresa dependem da legitimidade e da credibilidade social que inspira. É muito mais que uma questão de marketing ou de imagem. Existem sistemas de legitimidade que permitem justificar as ações empresariais e cuja ausência amplia de forma extraordinária a incerteza de seu horizonte futuro. O que está em jogo vai além das disposições morais de cada empresário individual: o importante é que há fenômenos sociais que interferem na própria organização industrial ${ }^{6}$.

Há um duplo fenômeno que a rígida oposição entre mercado e sociedade civil, dinheiro e vínculos sociais genuínos impede de levar em conta. Por um lado, é crescente a esfera mercantil de atividades específicas e qualificadas por atributos ambientais ou sociais: é o caso do comércio justo, da economia solidária (cf. Singer, 2002) e de inúmeros selos ambientais (cf. Conroy, 2007; Carneiro, 2006). Mais importante - como bem mostra Karpik (2007) - é o fato de uma quantidade crescente de produtos exigirem algum tipo de qualificação que se apoia em contatos pessoais ou em densas redes sociais: é o caso, por exemplo, da busca de um psicanalista, de um advogado, de um bom restaurante, de um bom vinho, de um produto ou um serviço ecologicamente sustentável. Por mais que seus preços contem, os mercados desses produtos não se formam com base nas mesmas regras que caracterizam os mercados de bens de massa e indiferenciados. Eles vão exigir modalidades de coordenação econômica que a visão convencional de mercado é incapaz de conter. Deverão ser qualificados, singularizados, e esse é um exercício que exige a construção de dispositivos de julgamento (cf. Karpik, 2007) que determinam a maneira como cada mercado monta seu regime de coordenação. Isso não importa apenas para os bens de luxo, mas também para mercadorias cuja qualidade social e ambiental é permanentemente questionada, como os biocombustíveis ou os transgênicos.

O estudo das singularidades, tal como proposto por Karpik (2007), faz parte de um longo percurso em que as ciências sociais dotam-se de meios 
para examinar os mercados sob o ângulo das qualidades e não fundamentalmente das equivalências. $\mathrm{O}$ aparato neoclássico com suas unidades autônomas e isoladas umas das outras é totalmente inadequado para isso. $\mathrm{O}$ importante é que o próprio mercado passa a ser visto como construção política, cultural, em cujas estruturas é permanente a intervenção consciente e voluntária dos atores. Nesse sentido, os mercados não são elementos de deterioração da cultura e da vida social, mas, ao contrário, são construídos permanentemente pela própria qualidade dos vínculos estabelecidos, em cada sociedade, entre os indivíduos e entre os grupos sociais. Os mercados não são os indevidos invasores da integridade cultural do mundo. Eles se encontram - como bem o provam os diferentes equipamentos sociais em que se apoia o julgamento das singularidades - entre os principais produtos da própria cultura humana. São, portanto, um espaço decisivo de atuação política cujo sentido não é forçosamente o de aniquilar a diversidade, exterminar a cultura e aviltar os laços sociais.

\section{Economia e intimidade}

O terceiro exemplo de um campo empírico que a sociologia econômica aborda de forma alternativa à visão de Gorz tem em Viviana Zelizer sua expressão mais emblemática. Aideia central de Zelizer $(1997,2004)$ é que o uso do dinheiro nas relações pessoais tem significado permanentemente construído e reconstruído pelos indivíduos e que fora de suas relações sociais concretas e específicas é impossível compreender e julgar se o dinheiro está entrando de forma invasiva para corromper costumes - como no tráfico de pessoas - ou se exprime apenas uma das muitas dimensões de que se compõem os laços humanos. As fronteiras entre o que é ou não aceitável são erguidas pelos indivíduos - e pelas organizações -, e nessas fronteiras eles definem suas próprias relações. O importante é que não existe uma esfera que pode ser definida em tese como externa ao mundo do dinheiro e outra em que só o dinheiro conta. Mesmo nas relações eróticas, a presença do dinheiro não é sempre e necessariamente sinal de prostituição, como bem mostra o trecho do último livro de Zelizer (2004), dedicado ao estudo do comportamento das taxi dancers dos anos de $1930^{7}$. Aoposição, nesse sentido, à maneira como Gorz (2003a, pp. 130-151) encara o trabalho de serviçal ou a prostituição não poderia ser mais nítida.

A base empírica do trabalho de Zelizer (2004) são processos na justiça norte-americana movidos por casais, por pessoas encarregadas de cuidados
7. Ver também o interessantíssimo artigo de Lopes Júnior (2005). 
8. Batista (2006) mostra que também no plano religioso o tratamento do dinheiro e da fé como mundos hostis ou do dinheiro como sintoma nefasto de corrupção das crenças genuínas pode ser fortemente colocado em questão no candomblé. domésticos e por conflitos domiciliares, desde o século XIX. A própria justiça é obrigada a elaborar categorias que lhe permitam julgar se presentes de noivado devem ser devolvidos ou se constituem uma espécie de indenização à ruptura do compromisso. Nos cuidados com pessoas necessitadas, Viviana Zelizer destrói a ideia tão frequente segundo a qual, se a dedicação é genuína, então não pode ser por dinheiro, e se for por dinheiro, é que não há dedicação. Seu livro mostra como a vida domiciliar é atravessada por relações que misturam permanentemente afeto e dinheiro, e que a separação rígida entre essas duas esferas provoca situações injustas como, por exemplo, a de considerar que o trabalho doméstico nada mais é que a expressão do afeto da mulher por sua família.

O trabalho de Zelizer é mais um exemplo dessa importante corrente do pensamento social contemporâneo - a sociologia econômica - que procura estudar a inserção do mercado na vida social e que abre um horizonte promissor diante do pessimismo decorrente da tese de que economia e sociedade civil são "mundos hostis" ou do conformismo contido na ideia de que tudo pode ser reduzido a interesses ${ }^{8}$. Se a economia está em nossa intimidade e se nossa intimidade contém dimensões econômicas fundamentais, isso significa que o dinheiro e o mercado não podem ser tomados como categorias claras e distintas cujo significado objetivo é o de nos distanciar necessariamente daquilo que somos e de nossas relações humanas mais verdadeiras. Portanto, influir sobre a maneira como se organizam os mercados, imprimir a essa organização conteúdos que não faziam parte das intenções iniciais de seus protagonistas é um meio decisivo de mudança social nos dias de hoje.

\section{Conclusões}

Talvez o mais importante pressuposto subjacente à diferença entre as abordagens de Gorz e a da sociologia econômica resida na maneira como é encarado o tema da liberdade humana e da autonomia do sujeito da ação social. Os três exemplos citados resgatam a postura sociológica que domina os trabalhos pioneiros de Ralf Dahrendorf (1991) e de Peter Berger (1991), para os quais não existe ação humana que possa ser caracterizada como livre, sob o ângulo científico: explicar a ação social significa sempre mostrar que ela está presa a determinantes que escapam ao domínio direto dos atores e, portanto, jamais pode exprimir a plena autonomia do sujeito. Todo espaço de ação social é, nesse sentido, para usar a expressão de André Gorz, 
necessariamente heterônomo. Naquilo que ele chama de esfera da autonomia estarão fatalmente escondidas relações de poder, de dominação, hierarquias, estruturas sociais, habitus (para falar como Bourdieu), formas de agir que o indivíduo incorpora independentemente de sua vontade e sobre as quais ele não tem e não pode ter completo e autônomo controle. A suposta autorregulação da vida social não pode ser um espaço livre, claro, visível, separado e independente de estruturas sociais. Inversamente, o que Gorz chama de esfera da heteronomia não opera senão com base em um conjunto de relações marcado pela mistura incessante entre vida pessoal e profissional, por redes que são localizadas e por vínculos que não se reduzem a uma dimensão estritamente mercantil.

Se isso é verdade, então é possível contestar fortemente a oposição básica - tão importante no trabalho de André Gorz - entre economia e sociedade civil, mercado e vínculos pessoais. É exatamente nesse sentido que Bruni e Zamagni (2007) contestam o mito de que o nascimento da economia moderna é marcado exclusivamente pelas trocas impessoais, anônimas, desprovidas de vínculos comunitários e funcionando tanto melhor quanto menos contaminadas pela política, pela ética ou pela moral. Para eles, os elementos fundamentais que estariam do lado da sociedade civil ou do mundo da vida (como a caridade, a reciprocidade e a dádiva) são centrais na própria história da formação dos mercados modernos. Bruni e Zamagni fazem uma reconstituição da história do pensamento social moderno e contemporâneo para mostrar que "a fisiologia, o funcionamento normal, a vocação do mercado é representar um momento da vida civil". É claro que o mercado pode ser e, de fato, tem sido profundamente anticívico e destrutivo, com a concentração da renda e a devastação ambiental, por exemplo. Mas essas patologias serão tanto mais severas quanto mais o mercado estiver separado do humanismo cívico que, segundo Bruni e Zamagni, está na sua origem. Público e privado, mercado e Estado, contrato e reciprocidade, interesse e dádiva: as ciências sociais podem convergir para superar essas oposições e, por aí, contribuir para a construção de um mundo em que os mais importantes valores éticos não estejam em confronto com o funcionamento real da vida econômica.

A principal consequência prática da atitude intelectual que insiste em encarar o mercado como imerso na vida social e não como esfera institucional autônoma (para utilizar os termos de Polanyi e Gorz) é que a ação política terá que se dirigir não apenas às organizações do Estado e da sociedade civil, mas também à própria maneira como se estruturam e agem as 
firmas. Não se trata de considerá-las domínios voltados exclusivamente aos lucros, mas, ao contrário, de interferir em seu funcionamento e na maneira como organizam os mercados em que atuam. O desafio central não está apenas em alargar o campo de empresas explicitamente guiadas por justiça, solidariedade e integração construtiva com os ecossistemas, e sim em fazer com que esses valores guiem - sob o efeito da pressão social organizada -0 conjunto da vida empresarial. É um objetivo político que não tem o encantamento da tomada do poder ou da ampliação da autonomia dos indivíduos com relação ao mercado; mas, ao mesmo tempo, é um meio de introduzir a cultura, a justiça, a natureza, em suma, a política, em domínios que a modernidade insiste, com sucesso cada vez menor, felizmente, em manter separados de maneira rigorosa.

\section{Referências Bibliográficas}

AznAR, Guy. (1995), Trabalhar menos para trabalharem todos. São Paulo, Scritta.

BATISTA, José Renato de Carvalho. (2006), “ 'Não se pode servir a Deus e a Mammon’: uma etnografia sobre os sentidos do dinheiro em ritos e festas do Candomblé". $30^{\circ}$ Encontro Anual da Anpocs, 24 a 28 de outubro. GT Sociologia Econômica.

BECKER, Gary. (1996), Accounting for Tastes. Cambridge, Harvard University Press.

BENKLER, Yochai. (2006), The Wealth of Networks How Social Production Transforms Markets and Freedom. New York/Lonon, Yale University Press. (Disponível em http://www.benkler.org, consultado em 25/07/2007.)

BERGER, Peter L. (1991), Perspectivas sociológicas : uma visão humanística. São Paulo, Vozes.

Bruni, Luigino \& Zamagni, Stefano. (2007), Civil Economy Efficiency, Equity, Public Hapiness. Oxford, Peter Lang.

CARneiro, Marcelo S. (2005), “O dinheiro é verde? ONGs e empresas na construção do mercado de madeiras certificadas na Amazônia brasileira". $29^{\circ}$ Encontro Anual da Anpocs, 25 a 29 de outubro de 2005. GT Sociologia Econômica.

CAstro, Ana Célia. (2007), "O catching-up do sistema agroalimentar brasileiro: fatos estilizados e molduras conceituais". $31^{\circ}$ Encontro Anual da Anpocs, 22 a 26 de outubro. Caxambu (MG). GT Sociologia Econômica.

CONROy, Michael. (2007), Branded! How the "Certification Revolution" is Transforming Global Corporations. Gabriola Island (Canada), New Society Publishers.

DAHRENDORF, Ralf. (1991), Homo sociologicus: ensaio sobre a história, o significado e a crítica da categoria de papel social. Rio de Janeiro, Tempo Brasileiro.

Elster, Jon. (1985), Making Sense of Marx. Cambridge, Cambridge University Press. 
Favareto, Arilson, Abramovay, Ricardo \& Magalhães, Reginaldo. (2007), “Direitos de propriedade, eficiência econômica e estruturas sociais em um mercado de bens culturais: o mercado de música brega no Pará". $31^{\circ}$ Encontro Anual da Associação Anpocs. Caxambu (MG), 22 a 26 de outubro. GT Sociologia Econômica.

Fuigstein, Neil. (2001), The Architecture of Markets: An Economic Sociology of TwentyFirst-Century Capitalist Societies. Princeton, Princeton University Press.

Gemici, Kurtulus. (2008), "Karl Polanyi and the Antinomies of Embeddedness”. SocioEconomic Review, 6: 5-33.

Gorz, André. (1974), "Leur écologie et la notre". Disponível no site http:// www.verts92.net/spip.php?article441, consultado em 20/3/2009.

. (2003a), Metamorfoses do trabalho: crítica da razão econômica. São Paulo, Annablume.

. (2003b), "Richesse, travail et revenu garanti". Disponível no site http:// www.etatsgeneraux.org/economie/textes/gorz1.htm, consultado em 17/5/2006.

. (2005), O imaterial: conhecimento, valor e capital. São Paulo, Annablume. . (2008), Écologica. Paris, Galilée.

Granovetter, Mark. (1985), "Economic Action and Social Structure: The Problem of Embeddedness". American Journal of Sociology, 91: 481-510.

. (2005), "The Impact of Social Structure on Economic Outcomes". Journal of Economic Perspectives, 19 (1): 33-50, inverno.

HABERMAS, Jürgen. (1987), Teoría de la acción comunicativa I: racionalidad de la acción y racionalización social. Madri, Taurus.

HoffMan, Andrew. (2001), From Heresy to Dogma: An Institutional History of Corporate Environmentalism. Stanford Business Books.

Hommel, Thierry \& Godard, Olivier. (2001), "Contestation sociale et stratégies de développement industriel: application du modèle de la Gestion Contestable à la production industrielle d'OGM". Cahier École Polytechnique, Laboratoire d'Économétrie, no 2001-15, http://ceco.polytechnique.fr/.

KARPIK, Lucien. (2007), L'économie des singularités. Paris, Gallimard.

Lerner, Josh \& Tirole, Jean (2002), "Some Simple Economics of Open Source”. The Journal of Industrial Economics, 1 (2): 197-234.

Lessig, Lawrence. (2001), The Future of Ideas: The Fate of the Commons in a Connected World. Nova York/Toronto, Random House. (Disponível em http://the-futureof-ideas.com, consultado em 02/4/2007.)

LOPES JÚNIOR, Edmilson. (2005), “Amor, sexo e dinheiro: uma interpretação sociológica do mercado de serviços sexuais". Política e Sociedade, 6: 165-193, abr.

Negri, Toni \& Cuoco, Giuseppe. (2006), "Bolsa-família é embrião da renda universal”. Folha de S. Paulo, 5/1/2006, p. A3. 
Polanyi, Karl. (1980), A grande transformação: as origens da nossa época. 3 ed. Rio de Janeiro, Campus.

Rifkin, Jeremy. (2004), O fim do emprego. São Paulo, M. Books do Brasil.

Singer, Paul. (2002), Introdução à economia solidária. São Paulo, Fundação Perseu Abramo.

STEINER, Philippe. (2000), "Marx et la sociologie économique". Cahiers Internationaux de Sociologie, CVIII: 57-77. (2006), A sociologia econômica. São Paulo, Atlas.

Suplicy, Eduardo M. (2002), Renda de cidadania: a saída é pela porta. São Paulo, Cortez.

Swedberg, Richard. (2003), Principles of Economic Sociology. Princeton, Princeton University Press.

TOURAINE, Alain. (2005), Un nouveau paradigme: pour comprendre le monde d'aujourd'hui. Paris, Fayard.

VAn PARIJs, Philippe. (1996), Refonder la solidarité. Paris, Cerf.

Weber, Max. (1991), Economia e sociedade. Brasília, Editora da UnB, vol. 1 .

Zelizer, Viviana A. (1997), The Social Meaning of Money: Pin Money, Paychecks, Poor

Relier, and Other Currencies. Princeton, Princeton University Press. . (2004), The Purchase of Intimacy. Princeton, Princeton University Press.

Resumo

Anticapitalismo e inserção social dos mercados

O artigo estabelece uma comparação entre André Gorz e alguns dos mais importantes autores da nova sociologia econômica. É verdade que se trata de um diálogo que nunca ocorreu de maneira explícita. O que torna a comparação relevante, porém, é que ela abre caminho para expor duas maneiras alternativas de encarar o tema sociológico básico da inserção dos mercados na vida social. Para Gorz, mercado e sociedade civil são termos antinômicos e não há tarefa política mais relevante que impedir a invasão, a colonização da vida social e das relações afetivas pelo mercado. Já para a sociologia econômica, ao contrário, os mercados estão completamente mergulhados na vida social, são por ela explicados e não podem ser considerados esferas institucionais autônomas. Dessa diferença na maneira de conceber a relação entre economia e sociedade decorrem consequências políticas fundamentais: para Gorz, as redes sociais que marcam a expansão dos softwares livres representam, potencialmente, o início de uma sociedade, não capitalista. Para a nova sociologia econômica, no próprio mercado é possível encontrar redes sociais baseadas em laços não mercantis. Além disso, a inserção social dos mercados convida a que a ação política se dirija não apenas ao setor 
público e associativo, mas também, e cada vez mais, à própria forma de se organizar o setor privado.

Palavras-chave: Sociologia econômica; Creative commons; Esquerda; Emancipação social.

Abstract

Anticapitalism and the social insertion of the marketplace

The article pursues a comparison between André Gorz and some of the most important authors from the new economic sociology. True enough, this dialogue never took explicit form. What makes the comparison relevant, though, is that it enables the exposition of two alternative ways of approaching the basic sociological theme of the insertion of markets in social life. For Gorz, market and civil society are antinomic terms and there is no more important political task than to prevent the invasion and colonization of social life and affective relations by the marketplace. For economic sociology, by contrast, markets are completely immersed in and explained by social life, and cannot be considered as autonomous institutional spheres. This difference in the way of conceiving the relationship between economy and society has fundamental political consequences: for Gorz, the social networks involved in the expansion of free software potentially represent the beginning of a non-capitalist society. For the new economic sociology, networks based on non-commercial relations can be encountered in the market itself. In addition, the social insertion of markets encourages political action to be directed not only towards the public and associative sector, but also increasingly the organization of the private sector itself.

Keywords: Economic sociology; Creative Commons; Left-wing; Social emancipation.

Texto recebido e aprovado em 24/3/2009.

Ricardo Abramovay é professor titular do Departamento de Economia da FEA/USP, coordenador de seu Núcleo de Economia Socioambiental (Nesa) e pesquisador do CNPq. E-mail: abramov@usp. br. 